\title{
Qualitative enquiry on the perceptions related to MCQ based discussion through WhatsApp status among medical students and teaching faculty during COVID-19 lockdown
}

\author{
Sunil Kumar Doddaiah, Praveen Kulkarni, Aparna Mohandas*, Narayana Murthy M. R.
}

Department of Community Medicine, JSS Medical College, JSS Academy of Higher Education and Research, Sri Shivarathreeshwara Nagara, Mysore, Karnataka, India

Received: 01 November 2020

Revised: 13 December 2020

Accepted: 25 December 2020

*Correspondence:

Dr. Aparna Mohandas,

E-mail: aparnacnair90@gmail.com

Copyright: (c) the author(s), publisher and licensee Medip Academy. This is an open-access article distributed under the terms of the Creative Commons Attribution Non-Commercial License, which permits unrestricted non-commercial use, distribution, and reproduction in any medium, provided the original work is properly cited.

\begin{abstract}
Background: Ever since the government of India announced countrywide lockdown, medical institutions across the country has shifted to virtual learning. Being in an era of smartphone users, the utility of a popular social media platform like WhatsApp in efficient learning needs to be explored. The aim of the study was to determine the perceptions related to multiple choice question (MCQ) discussion through WhatsApp status among medical students and teaching faculty.

Methods: This longitudinal study was conducted among 154 participants (medical students and faculty) for three months. MCQs on COVID-19 were disseminated through WhatsApp status of the investigator and feedback regarding the same was taken at the end of three months. The qualitative data collected as descriptions were compiled and analyzed as per classical content analysis. Specific codes were assigned to responses and were put under different categories with similar characteristics.

Results: A total of 154 participants took part in the study. Participants felt that the approach to convert a popular social media like WhatsApp to a learning platform was innovative. According to them, the activity motivated them to learn more and kept them updated on COVID-19. A major advantage of WhatsApp based learning, being that it can be used anytime and anywhere, which is relevant in the lockdown period.

Conclusions: In this study, participants found learning via WhatsApp to be interesting and motivating. Learning through this platform helped the participants to keep themselves engaged in the academics in spite of lockdown and also provided opportunity to clarify their doubts.
\end{abstract}

Keywords: COVID-19, MCQ, Medical education, WhatsApp

\section{INTRODUCTION}

The novel corona virus disease forced China and many other countries across the world to impose a lockdown. ${ }^{1}$ Two months after the disease was notified, on March 11, 2020, COVID-19 was declared as a pandemic by the World health organization. By then there were 1, 18,000 cases across 114 countries and 4291 people had succumbed to death. ${ }^{2}$
India reported its first case on 30th January, 2020, a medical student who returned from Wuhan after the epidemic started. ${ }^{3}$ Cases soon began to rise reaching a total of 563 and the Government of India announced countywide lockdown with effect from 25th March, 2020. ${ }^{4}$ Measures included cancelling public transport, restriction of movement, strict curfew, social distancing, cancelling mass gathering and closing down of offices, schools and colleges, including medical colleges. ${ }^{1}$ This 
was challenging as far as medical education is concerned as, for one, India has the largest number of registered medical colleges and it's important to maintain continuity of medical education and secondly, acquisition of clinical skills is imperative which is hard to meet through virtual mode. ${ }^{5,6}$

Medical council of India (MCI) has long stressed that medical education is a continuous process and students' need to constantly acquire new skills and acknowledges the importance of e-learning to achieve the competencies. Ever since, institutions across the country have supplemented regular teaching methods with e-learning with more weightage to cloud based learning. ${ }^{7}$ However, being in an era of smartphone users, wherein the younger generation tends to spend a longer time on social media, the utility of social media in effective learning needs to be looked into. ${ }^{8}$

WhatsApp messenger is equally popular among all generations as it is a free application and extremely user friendly. It is available across android and iPhone platforms, and makes it easy to share text, documents, images, audio and videos in real time. WhatsApp provides an interactive platform for teachers and students to share information and discuss it further. ${ }^{8,9}$ Considering all these, the aim of the study was to determine the perceptions of students and teaching faculty regarding a WhatsApp based multiple choice question (MCQ) discussion on COVID-19.

\section{METHODS}

The present longitudinal study was conducted for the period of three months from March 2020 to June 2020, after obtaining approval from the Institutional Ethics Committee.

\section{Study population and method of data collection}

Study was conducted among medical students, interns, Post Graduates and teaching faculty who voluntarily attempted the multiple-choice questions (MCQ) posted on the WhatsApp status of the principal investigator. Convenient sampling was used. Responses from 154 medical students, interns, Post Graduates and teaching faculty who participated daily during this period were included and those responses received from subjects other than these were excluded.

MCQs were framed by the experts who have formally received training in designing and implementing MCQs through the medical education Unit. MCQs were based on epidemiology, management, prevention and control of COVID-19. Each MCQ was prepared with a stem and four responses, out of which one was the right answer and three were distractors. Recall based, case scenario related, calculation based, picture based questions were framed. Each MCQ framed by the faculty was validated by the other faculty member before releasing for the participants to respond.

One MCQ per day was disseminated to the study participants through WhatsApp status of principal investigator so that participants' had sufficient time to understand the question and refer to relevant resources. The participants were invited to discuss any doubt, query, or clarifications in the process of solving the MCQ with the faculty. The correct answer to the MCQ was displayed on the same WhatsApp status wall 24 hours after the release of question. Activity $\log$ of the status with number of participants attempting the activity was maintained.

After three months, feedback was obtained from the participants using an open ended questionnaire including items on what went well during these sessions, what are the areas of improvements and suggestions to make this mode of learning more effective. The questionnaire was sent through an online google survey form, the link of which was shared on the same WhatsApp status wall where the MCQs were posted. The survey was kept active for one week from the starting date to provide enough time for the participants to respond.

\section{Data analysis}

The information was downloaded in the form of .csv (comma separated value) file and then transferred to MS excel-2010 for analysis. Descriptive statistics like percentages and mean were used. The qualitative data collected as descriptions were compiled and analyzed as per classical content analysis. Specific codes were assigned to responses and were put under different categories with similar characteristics. Verbatim of the participants involved in the study were also depicted. The entire analysis was done manually by two investigators trained in qualitative data analysis and consensus was arrived for depicting final results.

\section{RESULTS}

\section{General characteristics of participants}

A total of 154 participants took part in the study. Majority of the participants were using WhatsApp over last five years and they used to spend almost 1.5 to 2 hours daily with this app. Among the 154 study participants responding to the feedback survey, $44 \%$ of the participants were males and $56 \%$ were females. $48 \%$ were under graduates, $10.4 \%$ were interns, $30.6 \%$ were post graduates and $11 \%$ were teaching faculty.

\section{Qualitative results}

\section{Suggestions for improvement}

Discussion of the MCQs: The question was displayed on the status and 24 hours later the answer to the question 
was displayed on the same status. Participants were free to clarify any query with the investigator. One of the main themes which arouse in the feedback was regarding the need to discuss the answers further.

"10-15 minutes of video conferencing per week can be done" (participant 1).

"Answers require explanation for why they are right or wrong" (participant 2).

"Group discussion and video conferencing can be done" (participant 3).

Participants also suggested that creating a WhatsApp group will be helpful. For one, this will help to retain the question and answer for further reference and for another it can be used as a platform to discuss the topic further.

"A WhatsApp group can be made where questions and answers (with brief context) should be put up to glance upon later on also" (participant 1).

"Create a group and post questions so that the questions $\&$ answers will be with the students \& more discussion will happen" (participant 2).

Number of questions: One MCQ per day strategy was used in the intervention so that participants would not be overburdened and had sufficient time to refer to other resources. Participants suggested that the number of questions can be increased, as they felt they had more time in the lockdown period.

"Can increase the number of questions since it's anyways a lockdown period and there is enough time to brush up our knowledge" (participant 1)

"5 questions per day quiz like, made with help of Google docs" (participant 2)

Resources: Few of the undergraduates expressed that they were unfamiliar with the terms used in the questions and hence suggested that the resources to be referred to, needs to be provided.

"A list of suggested resources could be provided with each MCQ answer” (participant 1)

"Since some of the target group are in third year, I wasn't able to understand some of the terms used in the questions and didn't understand which chapter to refer to for more knowledge on the topic. Maybe after the answer to a question is revealed, some additional information about that topic can be provided so that reading up about it in the textbook becomes easier" (participant 2).

Sharing of MCQs with answers: Participants suggested that all the MCQs with answers if made available will help for future references.
"It would have been having been good if we get printed copies of such questions." (Participant 1)

"Kindly make all the questions available at one platform, it would be of great help in future referencing" (Participant 2).

Platform: We used WhatsApp status based exercise, some participants suggested WhatsApp groups as an alternative as the status disappears in a day and through groups it is possible to retain the questions and answers as well as it provides a platform for discussion.

"Another platform, because there are too many status from other people" (Participant 1)

"Group can be created instead of asking questions as status, may not open status all the time, if questions are asked in group students can access to any question at any time they are free, that'll help us" (Participant 2)

"I prefer WhatsApp group over WhatsApp status for MCQ, because through group we can have better discussions." (Participant 3)

"Maybe we can have a WhatsApp along with the status, so that the questions and answers can be there together as a collection of questions in a particular group. Since WhatsApp status disappear after 24 hours, so one can't go through the questions again or revise them for exams until a screenshot is taken." (Participant 4).

Variety of questions: Participants suggested that to make the exercise more interesting, variety of questions can be incorporated.

"Better variety of questions could be approached" (Participant 1)

"Image based or graph analysis type questions to be included" (Participant 2)

"More questions but in the form of connections, riddles, pictures to make it more interesting" (Participant 3)

Another suggestion given was that similar activities can be continued with other topics.

"continue theme based each month after corona stops and compile as MCQ resource" (participant 1) "cover more topics and subtopics" (participant 2)

Inter-departmental activity: It was suggested that activity can be extended, so as to include more departments in a group, to make discussion more comprehensive.

"Can be done by other departments. Or maybe like a college group with such discussions." (Participant 1)

What was best about the intervention? 


\section{Good utilization of time in Lockdown:}

The majority of the participants felt that the intervention was an effective way of utilizing time in lockdown period.

"To utilise the lockdown time by learning and practising something new. Make use of this time in a productive way." (Participant 1)

"Also, a good exercise to brain storm when getting bored or otherwise." (Participant 2)

"Best way to gain knowledge in a lockdown period." (Participant 3)

Updates on COVID-19: Participants felt that the intervention was useful in keeping them updated on epidemiology and guidelines related to COVID-19.

"Being aware and updated of the current pandemic." (Participant 1) "getting to know more about the disease and recent guidelines." (Participant 2)

"It helped me to get a better idea about the virus and COVID-19.” (Participant 3)

A participant responded that the exercise motivated them to refer more resources.

"Have basic and sound knowledge about pandemic and this exercise is motivating us to read more". (Participant 1)

Knowledge: Participants were of the opinion that the exercise helped them in gaining knowledge and it was assessed as well, on a daily basis.

"Daily assessment of knowledge." (Participant 1)

"Gaining knowledge when we're away from college." (Participant 2)

A participant felt that the exercise helped with the problem solving capacity.

"Knowledge base, thinking capacity and to solve question.” (Participant 1)

Another participant said that since they already spend a good deal of time on WhatsApp and the activity was through the same, they were benefitted.

"Due to lockdown we spend more time on this app. So it was good to spend some time gaining knowledge through the app." (Participant 1)

About the initiative: Participants felt that the approach to convert a popular social media like WhatsApp to a learning platform was innovative. It supplemented the regular learning in an interesting way.

“A very good initiative.” (Participant 1)

"Innovative and Informative" (participant 2)

"It became a good platform for learning and sharing new information.” (Participant 3)

"The effort from moderator's side is appreciable. Sir answered all the doubts immediately." (Participant 4)

"Good initiative and one of the best intervention taken to help med students ... Most of the students Take social media as a distraction but helping them to do both, take a break and gaining knowledge meanwhile.” (Participant 5)

Learning: Majority of the participants felt that the approach to learning in this activity was interesting, which motivated them to learn more.

“Active participation with learning." (Participant 1)

"Different and interesting way of learning." (Participant 2). "Easy way to learn a concept." (Participant 3) "Motivates to learn more" (Participant 4)

Advantages: The participants felt that the intervention had many advantages. The main being the convenience, since it was through a platform which they used daily.

\section{“Convenient" (Participant 1)}

"Easier access and concise information" (Participant 2)

"Easy way to gain knowledge and improve confidence" (Participant 3)

"Interactive method of studying" (Participant 4)

"Through these MCQs we could learn and revise the concepts of epidemiology" (Participant 5)

"Helped in reasoning and analysing" (Participant 6)

About the process: Participants felt that this activity motivated them to learn more and enhanced their knowledge.

"Encouragement to study more about the disease and community medicine." (Participant 1)

"Questions were logical helping me enhance my knowledge." (Participant 2)

"Meticulous work by the framer is commendable." (Participant 3) 
Learning various concepts in community medicine:

Participants felt that this was a great way of learnings various concepts of Community Medicine.

"It piqued your interest as it applied whatever we have learnt in community medicine to our current state of the world" (Participant 1)

"It was a very good method to learn community medicine. Since it used the current world crisis, it made the entire subject more interesting." (Participant 2)

"Horizontal and Vertical integration of PSM" (Participant 3)
Helpful for entrance exams: A major theme which came up was that, it helped them focus on preparing for competitive examinations.

"It reminded me to start preparing for PG entrance" (Participant 1)

"We became more confident solving MCQs day by day" (Participant 2)

"It will be helpful for NEET PG entrance exam" (Participant 3)

The responses of the participants with categories are represented in Table 1, 2 .

Table 1: Participant's responses with categories for suggestions on improving the method for effective learning.

\begin{tabular}{|c|c|c|}
\hline \multicolumn{2}{|c|}{ Categories } & Responses of the participants\# \\
\hline \multirow{5}{*}{1} & \multirow{5}{*}{ Discussion } & 10 to 15 minutes of video conferencing per week can be done. \\
\hline & & answers require explanation for why they are right or wrong \\
\hline & & Group discussion and video conferencing can be done \\
\hline & & $\begin{array}{l}\text { Create a group and post questions so that the questions } \& \text { answers will be with the students } \& \\
\text { more discussion will happen }\end{array}$ \\
\hline & & $\begin{array}{l}\text { Takes too long for the answers. Answers should have been posted along with the question in the } \\
\text { next status }\end{array}$ \\
\hline \multirow[t]{2}{*}{2} & \multirow{2}{*}{$\begin{array}{l}\text { Number of } \\
\text { questions }\end{array}$} & $\begin{array}{l}\text { Can increase the number of questions since its anyways a lockdown period and there is enough } \\
\text { time to brush up our knowledge }\end{array}$ \\
\hline & & 5 questions per day quiz like, made with help of Google docs \\
\hline \multirow[b]{2}{*}{3} & \multirow[b]{2}{*}{ Resources } & A list of suggested resources could be provided with each MCQ answer \\
\hline & & $\begin{array}{l}\text { Since some of the target group are in third year, I wasn't able to understand some of the terms } \\
\text { used in the questions and didn't understand which chapter to refer to for more knowledge on the } \\
\text { topic. Maybe after the answer to a question is revealed, some additional information about that } \\
\text { topic can be provided so that reading up about it in the textbook becomes easier }\end{array}$ \\
\hline \multirow[b]{2}{*}{4} & \multirow[b]{2}{*}{ Preserve } & It would been have been good if we get printed copies of such questions. \\
\hline & & $\begin{array}{l}\text { Kindly make all the questions available at one platform, it would be of great help in future } \\
\text { referencing. }\end{array}$ \\
\hline \multirow{4}{*}{5} & \multirow{4}{*}{ Platform } & Another platform, because there are too many status from other people \\
\hline & & $\begin{array}{l}\text { Group can be created instead of asking questions as status, may not open status all the time, if } \\
\text { questions are asked in group students can access to any question at any time they are free, that'll } \\
\text { help us }\end{array}$ \\
\hline & & $\begin{array}{l}\text { Since WhatsApp status disappear after } 24 \text { hours, so one can't go through the questions again or } \\
\text { revise them for exams until a screenshot is taken. }\end{array}$ \\
\hline & & $\begin{array}{l}\text { Maybe a google docs can be used to have MCQ session each and maybe it would be useful if all } \\
\text { the subjects follow the same pattern. It's a great initiative by our faculties. }\end{array}$ \\
\hline \multirow{6}{*}{6} & \multirow{6}{*}{ Questions } & Cover more topics and subtopics \\
\hline & & Can be more case based. \\
\hline & & Continue theme based each month after corona stops and compile as MCQ resource \\
\hline & & Cover all kinds of community medicine questions \\
\hline & & Image based or graph analysis type questions to be included \\
\hline & & More questions but in the form of connections, riddles, pictures to make it more interesting" \\
\hline 7 & $\begin{array}{l}\text { Inter- } \\
\text { departmental } \\
\text { activity }\end{array}$ & nents. Or maybe like a college group with such discussions. \\
\hline
\end{tabular}

\# Responses with similar context has been merged 
Table 2: Participant's responses with categories on what was best about the intervention.

\begin{tabular}{|c|c|c|}
\hline \multicolumn{2}{|c|}{ Categories } & Responses of the participants\# \\
\hline \multirow[t]{2}{*}{1} & \multirow{2}{*}{ Lockdown } & $\begin{array}{l}\text { To utilise the lockdown time by learning and practising something new. Make use of this time in } \\
\text { a productive way. }\end{array}$ \\
\hline & & Best way to gain knowledge in a lockdown period \\
\hline \multirow{3}{*}{2} & \multirow{3}{*}{$\begin{array}{l}\text { About } \\
\text { disease }\end{array}$} & Being aware and updated of the current pandemic. \\
\hline & & Getting to know more about the disease and recent guidelines \\
\hline & & Have basic and sound knowledge about pandemic and this exercise is motivating us to read more \\
\hline \multirow{4}{*}{3} & \multirow{4}{*}{ Knowledge } & $\begin{array}{l}\text { Due to lockdown we spend more time on this app. So it was good to spend some time gaining } \\
\text { knowledge through the app. }\end{array}$ \\
\hline & & Daily Assessment of knowledge \\
\hline & & Gaining knowledge when we're away from college \\
\hline & & Knowledge base, Thinking capacity and to solve question \\
\hline \multirow{6}{*}{4} & \multirow{6}{*}{$\begin{array}{l}\text { About the } \\
\text { initiative }\end{array}$} & Informative \\
\hline & & Innovative \\
\hline & & It became a best platform for learning and sharing new information \\
\hline & & $\begin{array}{l}\text { It is an extra effort from the teachers for us which helps us to evaluate our knowledge based on } \\
\text { our theory learning }\end{array}$ \\
\hline & & sir answered all the doubts on the spot \\
\hline & & $\begin{array}{l}\text { Good initiative and one of the best intervention taken to help med students ... Most of the } \\
\text { students Take social media as a distraction but helping them to do both, take a break and gaining } \\
\text { knowledge meanwhile.. Hope everyone will make the best out of it }\end{array}$ \\
\hline \multirow{3}{*}{5} & \multirow{3}{*}{ Learning } & Active participation with learning \\
\hline & & Different and interesting way of learning \\
\hline & & Easy way to learn a concept \\
\hline \multirow{10}{*}{6} & \multirow{10}{*}{ Advantages } & Convenient \\
\hline & & Easy and cover broader aspect of topic \\
\hline & & Helped in reasoning and analysing \\
\hline & & Interactive method of studying \\
\hline & & Kept engaged during real time situations \\
\hline & & Makes us curious \\
\hline & & Motivates us to learn more \\
\hline & & Novelty \\
\hline & & Through these MCQs we could learn and revise the concepts of Epidemiology. \\
\hline & & Was able to brush up Community Medicine once again \\
\hline \multirow{3}{*}{7} & \multirow{3}{*}{ Process } & Encouragement to study more about the disease and community Medicine \\
\hline & & Questions were logical helping me enhance my knowledge. \\
\hline & & Meticulous work by the framer is commendable \\
\hline \multirow{2}{*}{8} & \multirow{2}{*}{$\begin{array}{l}\text { Learning of } \\
\text { Community } \\
\text { Medicine }\end{array}$} & $\begin{array}{l}\text { It piqued your interest as it applied whatever we have learnt in community medicine to our } \\
\text { current state of the world. }\end{array}$ \\
\hline & & $\begin{array}{l}\text { It was a very good method to learn community medicine. Since it used the current world crisis, it } \\
\text { made the entire subject more interesting. }\end{array}$ \\
\hline \multirow{3}{*}{9} & \multirow{3}{*}{$\begin{array}{l}\text { Helpful for } \\
\text { entrance } \\
\text { exam }\end{array}$} & It will be helpful for NEET PG entrance exam \\
\hline & & It reminded me to start preparing for my PG \\
\hline & & We become more confident solving the MCQs day by day \\
\hline
\end{tabular}

\section{DISCUSSION}

WhatsApp is a widely used social media platform by teachers and students, hence the need to explore more on its utility in learning, especially in this lockdown period was essential. In this study we tried to assess the perceptions of students and faculty regarding WhatsApp based MCQ discussion on COVID-19. The MCQs were displayed on the investigators' status and 24 hours later the answer was displayed. Participants felt the need for discussing answers further, either through video conferencing or a WhatsApp group. They felt that WhatsApp group discussion would promote better interaction and that discussions can be used for future reference. Roy et al, in his study reports that the major advantage with WhatsApp based learning being "the resources remaining forever". ${ }^{10}$ 
A major drawback of WhatsApp status being that it disappears in 24 hours, participants felt that they might miss it when there are too many statuses from other contacts. Hence, they suggested an alternate of WhatsApp group for the exercise. The messages posted in them can be read anytime according to their convenience and that they can involve in further discussion about the topics.

The use of WhatsApp for learning was well appreciated by the participants who felt that similar activities can be extended to other topics, involving the faculties from various departments. This will help in an integrated learning environment. Mohesh et in a study among first year medical students reported that the majority of the students suggested the use of WhatsApp based learning in all the subjects and that a WhatsApp group can be used to supplement classroom teaching to raise queries and discuss the subject further. ${ }^{11}$

COVID-19 pandemic has also seen an avalanche of information. Some of which were inaccurate, causing confusion and anxiety among the people. ${ }^{12}$ In this study, the MCQs were prepared by experts, relating to epidemiological aspects, guidelines and management of COVID-19, which helped the participants in keeping updated on COVID-19 in the best way.

The participants used WhatsApp on an average of 1.5 to 2 hours per day. They felt that this time of WhatsApp use was put to good use to gain knowledge and this was assessed on a daily basis as well. According to the participants, this approach to utilize a commonly used media like WhatsApp, where they already spend a large amount of time to a learning platform was quite innovative. This made learning more interesting, motivating them to refer other resources and promoting active, self-directed learning. Literature suggests that WhatsApp based learning is a good way to promote selfdirected learning. Nanda et al reported that due to the interest that the students develop through WhatsApp based learning, it significantly improved their knowledge level and writing skills. ${ }^{13}$ Zulfikar et al also reported that students felt WhatsApp based discussion was a motivation for learning. ${ }^{14}$ Compared to the conventional methods, a major advantage of using a WhatsApp like platform is that students can discuss and clarify their doubts almost immediately. Besides this, participants felt that this method was convenient, as they could use it anytime, anywhere, similar to the findings of Guo et al. ${ }^{15}$ Participants responded that the intervention, enhanced reasoning and problem solving skills and they felt confident in answering MCQs which would help them in preparing for competitive exams. Grover et al reported that after a WhatsApp based intervention students felt they could perform better in MCQ exams. ${ }^{16}$

\section{CONCLUSION}

In this study, participants found learning via WhatsApp to be interesting and motivating. The learning through this platform helped the participants to keep themselves engaged in the academics in spite of lockdown and also provided opportunity to clarify their doubts regarding the subject. Majority of the participants recommended to continue this intervention in interdisciplinary manner by including more number of faculty members.

Funding: No funding sources

Conflict of interest: None declared

Ethical approval: The study was approved by the Institutional Ethics Committee

\section{REFERENCES}

1. Paital B, Das K, Parida SK. Inter nation social lockdown versus medical care against COVID-19, a mild environmental insight with special reference to India. Sci Total Environ 2020;138914.

2. WHO Director-General's opening remarks at the media briefing on COVID-19 - 11 March 2020 [Internet]. [cited 2020 Aug 15]. Available at: https://www.who.int/dg/speeches/detail/whodirector-general-s-opening-remarks-at-the-mediabriefing-on-covid-19. Acceessed on 11 March 2020

3. Bhatnagar T, Murhekar MV, Soneja M, Gupta N, Giri S, Wig N, et al. Lopinavir/ritonavir combination therapy amongst symptomatic coronavirus disease 2019 patients in India: Protocol for restricted public health emergency use. Ind $\mathbf{J}$ Med Res 2020;151:184.

4. Priyanka P. Covid-19: India imposes lockdown for 21 days and cases rise. Bio Med J. 2020;368:1251

5. Anjali S, Sanjay Z, Bipin B. India's foreign medical graduates: an opportunity to correct India's physician shortage. Educ Heal. 2016;29:42-6.

6. Saiyad S, Virk A, Mahajan R, Singh T. Online teaching in medical training: Establishing good online teaching practices from cumulative experience. Int $\mathbf{J}$ Appl Basic Med Res. 2020;10(3):149.

7. Dhir SK, Verma D, Batta M, Mishra D. E-learning in medical education in India. Indian pediatr. 2017;54(10):871-7.

8. Latif MZ, Hussain I, Saeed R, Qureshi MA, Maqsood U. Use of Smart Phones and Social Media in Medical Education: Trends, Advantages, Challenges and Barriers. Acta Inform Medica. 2019;27:133.

9. Gon S, Rawekar A. Effectivity of E-Learning through WhatsApp as a Learning Tool. MVP J Med Sci. 2017;4:19-25.

10. Roy H, Ray K. "WhatsApp"-A Supplementary Teaching Method In Anatomy For First Year Medical Students And Students' reflection On It. Int J Sci Res. 2019;8.

11. MI GM, Meerasa SS. Perceptions on M-learning through WhatsApp application. J Educ Technol Health Sci. 2016;3:57-60.

12. The Lancet Infectious Diseases. The COVID-19 infodemic. Lancet Infect Dis. 2020 Aug;20(8):875. 
13. 13. Nanda MS. Role of WhatsApp in improving learning among medical students. Int $\mathrm{J}$ Med Sci Public Heal. 2019;8.

14. Zulfikar I, Zaheer F, Baloch Q, Ahmed F. The new face of learning: Social media innovating medical education. Int J Educ Psychol Res. 2018;4:1-5.

15. Guo, France X, Matthew, Cowley, Paul. Using Whatsapp to Enhance Students' Learning: A Cohort Analysis at A Uk University. 2020;8304-13.

16. Grover S, Garg B, Sood N. Introduction of casebased learning aided by WhatsApp messenger in pathology teaching for medical students. J Postgrad Med. 2020;66(1):17.

Cite this article as: Doddaiah SK, Kulkarni P, Mohandas A, Murthy NMR. Qualitative enquiry on the perceptions related to mcq based discussion through whatsapp status among medical students and teaching faculty during COVID-19 lockdown. Int J Community Med Public Health 2021;8:678-85. 